ISSN electrónico: 2602-8069

\title{
LA MARCA PERSONAL, UN DESAFÍO PARA LOS PERIODISTAS ECUATORIANOS
}

Personal branding, a challenge for the ecuadorian journalists

Samuel Yánez

Universidad UTE

syanez@ute.edu.ec

Mayra Martínez

Universidad UTE

mmartinez@ute.edu.ec

Renato Barros

Universidad UTE

rbarros@ute.edu.ec

\section{Artículo científico}

Fecha de recepción del artículo: 12/2018

Fecha de aceptación definitiva: 28/12/2018 


\section{La marca personal, un desafío para los Periodistas Ecuatorianos}

\section{RESUMEN}

La marca personal es un factor clave para generar prestigio, los periodistas ecuatorianos han logrado este valor en medios de comunicación tradicionales, sin embargo, muchos de ellos no han recurrido a herramientas digitales para fortalecer su identidad en la red, y ganar autonomía respecto al medio.

El presente estudio analiza la marca personal del periodista, en la relación identidadvisual, e identidad-digital con el uso de plataformas como Twitter, Facebook e Instagram.

La metodología aplicada permitió identificar el uso de la marca personal mediante el análisis de contenido de carácter descriptivo, sistemático y cuantitativo de la información; todo esto se lo realizó mediante un monitoreo de las redes sociales de periodistas destacados que han incursionado en el campo del branding personal.

Se concluye que la gran mayoría de los periodistas ecuatorianos no han mostrado interés en la construcción de su marca personal, no han trasladado su nombre a plataformas digitales, son reconocidos por el programa o por el noticiero en que se presentan ante la audiencia, y no precisamente por quién es y lo que representa. Muy pocos han empezado a construir su marca personal, han aceptado el desafío de crear y mantener su identidad digital.

Palabras clave: Marca; identidad digital; marca personal; periodista

\section{ABSTRACT}

Personal branding is a key factor to generate prestige, Ecuadorians journalists have achieved this value in traditional media; however, many of them have not resorted to digital tools, to strengthen their identity in the network and gain autonomy and positioning on media.

The present study analyzes the personal brand of the journalist in the relationship visual identity and digital identity with the use of platforms such as Twitter, Facebook and Instagram.

The methodology applied allowed to identify the use of the personal brand through the analysis of descriptive, systematic and quantitative content of the information; monitoring of social networks of prominent journalists who have dabbling in the field of personal branding.

It is concluded that the majority of Ecuadorian journalists have not shown interest in building their personal brand, they have not transferred their names to digital platforms, and are recognized by the TV shows or the news; and not precisely for who he is and what he represents. Few have begun to build their personal brand and have accepted the challenge of creating and maintaining a digital identity.

Keywords: mark; digital identity; brand staff; journalist 


\section{Introducción}

«Marcar significa dejar una impresión inolvidable en la mente de alguien, es algo que merece la pena ser recordado, o actuar sobre alguien o sobre algo dejando huella moral.» (Losada, 2010).

La necesidad de diferenciación hizo que surgiera el marcado, su origen puede situarse en una práctica de los ganaderos que marcaban a sus animales para distinguirlos; o en el de los artesanos y comerciantes que ponían sus iniciales o sencillos símbolos abstractos para establecer credibilidad y garantía sobre el producto, evitar confusiones y en muchos casos que los artesanos se sintieran orgullosos y valoraran su trabajo.

Esta idea primitiva de distinción ha evolucionado y adaptado, hasta el desarrollo de la marca como la conocemos en la actualidad, uno de los signos más importantes de la sociedad moderna. En el área comercial, las marcas surgieron para diferenciar productos que podrían ser parecidos o difíciles de distinguir. La marca no está relacionada con un objeto físico, sino con características que se desean endosar al signo visual, con fuerte contenido semiótico, integrado por elementos como formas, textos, colores, sonidos, conceptos, emociones, sentimientos, etc., elementos dispares que pueden ya haberse utilizado en otros contextos, pero, que al ordenarlos en formas diferentes, logran generar significados específicos para grupos específicos de personas.

La marca debe tener contenido e identidad, esta se convierte en un discurso social, colectivo y público; para su existencia requiere una presencia pública que se desarrolla en contextos de exposición, recepción y consumo definidos, por tal motivo, la marca plantea diferentes discursos orientados a los actores involucrados.

En la Revolución Industrial, las marcas empiezan a cobrar protagonismo como signos gráficos e identificativos, se posiciona como la expresión de identidad de la empresa, un elemento visual que pretende que el público lo asocie instantáneamente a lo que representa. En la actualidad, se tiende a confundir marca con logotipo. La marca es mucho más que un producto o un servicio y también es mucho más que un simple nombre o logotipo. La marca constituye las sensaciones que despiertan un producto, una empresa o una persona.

En la llamada Segunda Revolución Industrial existió una sobreproducción de bienes y servicios que dio paso al desarrollo de disciplinas como el marketing y la publicidad, estas propiciaron a que se diseñe profesionalmente el producto, su presentación, y su comunicación, lo que hace, lo que dice y cómo se comporta la organización y sus integrantes, para transmitir una determinada imagen.

Según Costa (2006), la imagen de la empresa es el efecto de causas diversas: percepciones, inducciones y deducciones, proyecciones, experiencias, sensaciones y vivencias de los individuos que, de un modo u otro, son asociados entre sí. Esta imagen es la que vende intangibles, pues ya no se expenden los productos por su valor material o de uso, sino por la interacción simbólica y de los valores que se generan. Se deja de vender y comprar productos para vender y comprar marcas.

La marca pasó de ser un medio de distinción o de marcaje a un símbolo de propiedad, identidad, apropiación y diferenciación, y pasó de ser algo que se comercia a algo que se comunica. Esto ha generado que los hábitos de consumo de los individuos, sus actitudes frente a los productos y los fabricantes se afecten, transformen o cambien frente a las tendencias sociales, culturales y económicas. Las organizaciones han 


\section{La marca personal, un desafío para los Periodistas Ecuatorianos}

comprendido que la cultura de la comunicación es fundamental y la desarrollan de acuerdo con su filosofía empresarial, al papel económico y social que desempeñan, a su visión, misión, valores y objetivos; que la comunicación requiere que todo discurso tenga un destinatario y que este genere una retroalimentación, una red de relaciones de escucha y diálogo con sus grupos de interés, así la marca se convierte en un actor social.

«La identidad de una marca es hoy el pilar sobre el que giran las máximas estrategias de promoción y desarrollo, pero esta identidad, como todas las identidades, no se logra aisladamente. La identidad de la marca, como la identidad de las personas, nace de una interrelación, brota de un cruce entre las sugerencias del emisor y las percepciones del receptor. Como consecuencia, pues, la pesquisa en pro de la identidad de la marca debe seguir una vía que incluya siempre a los posibles clientes como consumidores y autores.» (Verd, 2007: 118)

En la identidad de la marca interactúan permanentemente la cultura y la filosofía corporativa, el contexto social, cultural, político, legal y económico, y las experiencias, actitudes y motivaciones del receptor. Costa (2006) señala que la marca es el resultado de un contexto dado y en un mercado puntual, por lo que es fundamental que la marca se renueve con el paso del tiempo.

La identidad de marca no debe ser ni desarrollada ni percibida como un simple mensaje que se transmite sino como un objeto semiótico, la marca es un sujeto discursivo que posee una autonomía significativa desarrollada con una serie de elementos que deben ser comprendidos por el receptor.

Esta comprensión no garantiza la aceptación en el mercado pues en la actualidad existe una saturación de marcas, por lo que una marca no solo requiere ser distinguida de otras, sino que además debe tener ciertos valores intrínsecos para que el usuario sienta algún nivel de relación con el objeto propio del producto.

Según Baños y Rodríguez (2012), la identidad de marca se conforma a partir de cuatro perspectivas:

«1. La marca como producto, que es la identificación de la marca en relación a las distintas posibilidades del producto que respalda. Es una parte nuclear de la identidad por la relación directa que mantiene con la necesidad y decisión de compra y con experiencia de uso.

2. La marca como organización, que se centra en los atributos de la empresa u organización y en su condición de "global versus local". Este componente de la identidad comunica atributos organizativos como innovación, búsqueda de calidad y preocupación por el entorno, que se plantean como el objetivo y campo de trabajo principal de la compañía u organización, constituyendo la cultura y valores de la misma.

3. La marca como persona, que sugiere para la misma una dimensión más profunda, interesante y conectada con lo emocional. Se trata de que la marca se pueda percibir, al igual que una persona, como dotado de cierta personalidad, entendida como rasgos psicológicos o valores, por ejemplo: amable, confiable, divertida, alternativa... y, en la misma medida que la personalidad humana marca las relaciones personales, la personalidad de marca ofrece la base de la relación marca y un cliente.

4. La marca como símbolo, que proporciona cohesión y estructura a la identidad favoreciendo el reconocimiento y el recuerdo de la misma. Su presencia, como elemento 
unificador y atractivo, es ingrediente clave para el desarrollo de la marca.» (Baños y Rodríguez, 2012: 50 -51)

\section{Marca personal}

Según Arqués (2011), marca personal es la manera de clarificar y comunicar aquello que nos hace diferentes y especiales, y de emplear esas cualidades para guiar nuestra carrera o tomar nuestras decisiones estratégicas. Es el reflejo de la cultura, manera de ser, creencias, habilidades, fortalezas y valores, todo esto motiva la percepción que tienen los demás sobre nosotros, marca propia que se muestra en lo que se hace y en el cómo se hace.

Los principios de manejo de marca son aplicables a productos, compañías, ciudades, países y personas. Todos cuidan su imagen y sus acciones para transmitir, de forma permanente, ciertas características como innovación, cambio o misterio, todo siempre con la misma intensión, de forma que cuando alguien los vea sepa de qué se trata.

Para Losada (2010), en la creación de marca personal se deben seguir las siguientes etapas, muy parecidas a la creación de marca corporativa o de productos:

1. Etapa filosófica: etapa de pensar. ¿Quién soy, qué hago, cómo lo hago, qué me gustaría hacer, cuál es mi visión del futuro, cómo me gustaría verme?

2. Etapa analítica. ¿Cómo están las cosas para lograr mis objetivos?

3. Etapa de toma de decisiones. ¿Qué es lo que podemos y vamos a hacer?

Para desarrollar una marca personal todo lo que se quiere comunicar se tiene que notar en lo que se hace, en el comportamiento y trabajo, pues, ninguna marca existe solo con un planteamiento teórico, sino que debe hacerlo de forma real, en sus actuaciones. Se orienta todo el accionar en la ventaja diferencial, así que todo lo que se diga y haga debe ir en la misma dirección. Las marcas de personas no son producto, por lo que el proceso de gestión de la marca debe hacerse teniendo en cuenta sus características irrepetibles y únicas.

La incorporación de las denominadas TIC, o nuevas tecnologías, en todas las profesiones han provocado un cambio, muchas veces traumático. Los profesionales, para darse a conocer, se ven en la obligación de desarrollar y perfeccionar una marca personal en diversas plataformas. Los perfiles de redes sociales, blogs, sitios web o portafolios ahora son para todos sin distinción alguna.

Al analizar Internet como medio de comunicación, podemos advertir que se encuentra regido por una lógica publicitaria. Su objetivo es atraer y atrapar la atención del público. La búsqueda de la rentabilidad y la necesidad de ser eficaces en la comunicación, ha llevado al mercado digital hacia una posición de poca reflexión y baja calidad en los contenidos.

El interés por conquistar un lugar en la mente de los usuarios de la red ha hecho que las marcas realizaran un esfuerzo comunicativo importante. En Internet, para construir una imagen de marca, es necesario tener experiencia de uso hay que realizar un mayor esfuerzo en el desarrollo y comunicación de aquellas actitudes y comportamientos que interesa asociar a las marcas porque, en definitiva, son las que le otorgan su significado.

En Internet, con frecuencia las marcas establecen su posicionamiento en valores aspiracionales, en una imagen de marca adquirida en el tiempo, en la confianza, la 


\section{La marca personal, un desafío para los Periodistas Ecuatorianos}

credibilidad o la satisfacción. Para Flórez (2012), las reglas de juego del mercado cambian rápidamente y lo digital lo está cambiando todo. Las estrategias digitales le permiten mejorar, a las marcas, la relación con sus públicos objetivos que cada vez está más formado e informado en el uso de los medios digitales. No solo es tener presencia en el mundo digital, también hay que saberlo enfocar para lograr los resultados esperados.

Los beneficios de establecer una marca digital se reflejan en la conexión directa con los clientes más allá de lo palpable, que les haga no solo comprar sino obtener su afecto y respaldo. Este concepto denominado e-branding orientado a hacer y construir marcas en los medios digitales, no es solo la creación de una imagen, sino que abarca desde la experiencia del usuario hasta el posicionamiento.

Cuando se establece una estrategia de e-branding, según Vanegas (s.f.) de dinterweb, hay que tener en cuenta que los usuarios se acostumbran rápido a una imagen o frase determinada, por lo que un simple cambio puede deshacer todo lo que costó años establecer. La marca no solo es un logo y nombre, sino también tiene cualidades físicas y emocionales. Transmitir cosas veraces, creíbles y transparentes, lo contrario provocará una mala reputación. En el mundo digital el cliente es el que impone las reglas, las marcas deben interactuar con ellos para conseguir el éxito.

\section{La marca personal del periodista}

Para establecer el principio de cómo nace la marca en los periodistas, debemos iniciar analizando a los medios de comunicación tradicionales: televisión, radio y prensa escrita. En los últimos 10 años, los medios tradicionales han tenido dificultades para mantener conectado a su público, y eso se puede medir en la baja de su rating y audiencia en el caso de la televisión y radio, además del declive de la circulación en los periódicos impresos. Según Sánchez (2017), la disminución de los lectores de periódicos deriva de varios factores, uno de ellos es la aparición de las nuevas tecnologías, las cuales han llevado a las personas a buscar información a través del Internet. Esto ha hecho que el periodismo, los medios de comunicación y el periodista busquen nuevas alternativas para conectar con los públicos y sobretodo dar a conocer su contenido. Internet ofrece mayor versatilidad para el consumo audio y video, mayor variedad de formatos y contenidos, y aporta al menor consumo de medios tradicionales. El periodismo está experimentando importantes transformaciones. Internet y los medios sociales juegan un papel cada vez más relevante en la distribución y el consumo de noticias. El público, por un lado, elige informarse a través de medios y plataformas digitales. Las empresas mediáticas, por su lado, padecen las consecuencias de esta tendencia, castigadas con menos inversión publicitaria y drásticas reducciones de beneficios. Esta crisis del modelo de negocio se traduce en salarios más bajos y despidos (Casero- Ripollés, 2010).

Es así que el Internet toma protagonismo y se crean nuevos medios de comunicación digitales y también aparecen nuevas formas de transmitir el contenido, entre los que se destaca el uso de blogs; las redes sociales como Facebook o Twitter, canales de YouTube, transmisiones en vivo, entre otros. Los periodistas y los medios utilizan estas herramientas para ser más cercanos a su audiencia. Aquí surge otro problema los periodistas generan información para el medio que laboran, y las comparten en sus cuentas personales, es aquí donde existe un enfrentamiento entre el profesional y el medio. Como dice Cobo (2012), la marca personal del periodista, y su generalización, está produciendo problemas en algunas redacciones que ven en la marca personal una amenaza para la marca del medio. Esto genera dudas en la audiencia ya que no saben quién realmente está generando la información o a quién deben seguir. No todos los medios de comunicación comparten el mismo criterio de los periodistas; sin embargo, 


\section{La marca personal, un desafío para los Periodistas Ecuatorianos}

existen otros medios de comunicación que han creado referentes periodísticos y los utilizan para tener una mayor reputación y credibilidad de su contenido, haciendo que la marca del periodista realce su imagen como medio.

Las redes y el Internet son un espacio donde el periodista debería sentirse más cómodo, porque puede publicar con mayor libertad al no existir restricción de espacio, aquí es donde los periodistas pueden crear un perfil propio, construyendo una reputación personal más cercana o no tanto al medio de comunicación donde trabajan.

El periodista que empieza a hacer una marca personal fuera del medio de comunicación debe tener claro el público y la audiencia al cual se quiere dirigir, debe entender cómo funcionan las redes sociales y las diferentes herramientas que usa el Internet para crear información, entender y capacitarse en el uso de otro tipo de software o programas de computación para producir contenidos más interactivos aplicando la multimedia. Como afirma Méndez, Romero, Somavilla (2016), los periodistas de marca deben aportar una propuesta de valor a su contenido y siempre deben actualizar la información en todas las plataformas que utilicen, tienen que describir coherentemente el objetivo y el tipo de periodista con el que quieren que la gente los identifique, en definitiva, tener un imagen sólida para ser reconocido a nivel profesional.

Se pueden destacar algunas características para hacer una buena marca de periodista:

- Ser auténtico, ser él mismo, sin disfraces ni maquillaje.

- Ser diferente, es muy difícil destacar siendo uno más del montón. Por eso deben especializarte en algún tema.

- Ser relevante, de nada sirve si el trabajo queda en el cajón, habrá que moverlo y darlo a conocer.

- Ser coherentes. No se puede ser cada día de una manera y en cada red actuar de forma diferente, o dar una imagen en el mundo digital que difiera de nuestra forma de ser fuera de la red.

- Ser claro, fácil de distinguir.

Es esencial acotar que la marca del periodista puede ser visto o seguido por pequeñas o grandes multitudes, esto dependerá de la gestión que el periodista le imprima a su marca en Internet y en las redes sociales, la primera visualización con la que los usuarios pueden acceder a la marca de un periodista es Google, como sostiene MuñozOlivencia (2015), un buen posicionamiento en este buscador atrae a un mayor número de visitas, es una estrategia para aquellas personas o empresas que desean tener éxito en Internet.

Hay dos formas de posicionarse en los motores de búsqueda a través del contenido orgánico que es un tipo de información que si a la gente le atrae, la comparte y se puede hacer viral en minutos o segundos, y el contenido de tipo publicitario o pagado que es la información que mediante un pago económico llega a difundirse, pero no es tan seguro que se viralice. En cambio, las redes sociales ayudan al periodista a difundir más rápido la información y tener contacto más íntimo con sus seguidores, porque puede responder e interactuar en tiempo real. Lo interesante es que sea cuál sea la estrategia que aplique, la producción de contenido, basado en una buena investigación, contraste de fuentes, una redacción creativa y propuestas multimedia, es sin duda el mayor aporte que el periodista debe aplicar para llegar a un mayor público. 


\section{La marca personal, un desafío para los Periodistas Ecuatorianos}

Para posicionar una marca personal también es importante otros aspectos orientados al marketing, la publicidad y el diseño gráfico, «la marca es el conjunto de valores, atributos y beneficios que el cliente percibe en nosotros y que le conducen a confiar y contratarnos o, en el lado negativo, a rechazarnos. Por lo tanto, todos esos elementos que componen la marca funcionan como signos distintivos en el mercado y nos diferencian de la competencia». (Estalella, 2011:32).

Como explica López-Meri y Casero-Ripollés (2017), la clave para construir una buena marca periodista son el posicionamiento, la curación de contenidos, la personalización y la especialización. Los nuevos tiempos digitales que estamos viviendo hacen repensar que el reto del periodista debe enfocarse en generar con su marca: innovación, creación y emprendimiento tener una marca personal que requiere de mucho trabajo, esfuerzo y sacrificio; en estos perfiles es fundamental mantener fuera los ámbitos familiares, tener una audiencia prestigiosa que crea en la palabra del periodista, sin estar en un medio masivo de comunicación, es lo que ha hecho la marca personal con el nuevo periodismo digital.

\section{Metodología}

El método utilizado es de carácter descriptivo, sistemático y cuantitativo de la información para analizar el manejo de la marca personal en los periodistas ecuatorianos con la finalidad de identificar y explicar el uso de la marca en cuanto a su imagen y contenido.

Se formuló una entrevista dirigida a 2 especialistas en marca, tecnología y comunicación. Se realizó una encuesta a 105 periodistas de distintos medios de comunicación ecuatorianos, con los datos obtenido se identificó a los profesionales que manejan marca entre ellos se destacan: Vito Muñoz, Alberto Astudillo, Andrés Guschmer, Diego Arcos, entre otros.

Así también se realizó un análisis de contenido a través del monitoreo de las redes sociales que manejan estos profesionales como Facebook, Twitter, Instagram, página web, para registrar el manejo de su contenido y marca.

\section{Objetivo}

Analizar el manejo de la marca personal en los periodistas ecuatorianos, su construcción visual y el desarrollo de los contenidos.

\section{Resultado de la investigación}

Al consultar a los periodistas ecuatorianos sobre si la marca personal es necesaria, un $71 \%$ afirma la importancia que tiene en el desarrollo de un profesional. Esta respuesta coincide con la entrevista proporcionada por Albertina Navas (2018), consultora en estrategia de redes sociales. Para ella «los periodistas deben tener una marca personal sobre todo desarrollada para medios digitales, esta no es solo una opción, sino algo que incluye su perfil profesional. Los periodistas son líderes de opinión influencian en redes sociales porque su trabajo orienta a la opinión pública» (Navas, 2018).

Sin embargo, no todos los periodistas han considerado esta opción, como lo afirma José Rivera, experto en comunicación y tecnología: "Los periodistas, sobre todo los tradicionalistas, no se han preocupado por su identidad digital y reputación, dos puntos entendidos básicos para lo que es una generación de marca: la identidad que es todo lo que yo público en redes sociales o en espacios sociales con el fin de construir una percepción sobre mí» (Rivera, 2018). 
En este sentido, construir una marca personal conlleva no solo el hecho de estar en los medios de comunicación tradicionalistas, sino avanzar hacia el uso de redes sociales. Para los periodistas consultados, estas herramientas deberían ser Facebook, Twitter, Instagram y página web, donde los profesionales debería trabajar en su imagen (logotipo, isotipo, cromática, línea gráfica) y en el contenido.

Estos, según Rivera (2018), serían los espacios óptimos para generar una identidad digital y construir marca personal. "Desde que yo empiezo administrar una red social, un blog, comentarios que publico, contenidos que son difundidos, de alguna forma me van encasillando en algo que yo quiero ofrecer.

Generar un sitio web, con un dominio, bajo mi nombre, es parte del esfuerzo que se realiza para poder ser visible en el mundo digital» (Rivera 2018).

Tomando como referencia la opinión del experto, se presenta la interrogante ¿Qué periodistas ecuatorianos han generado marca personal? Para los profesionales encuestados serían: Alberto Astudillo, Vito Muñoz, Diego Arcos, Andrés Guschmer, Alfonso Espinoza de los Monteros, Carlos Víctor Morales, Estefany Espín, Juan Carlos Aizprúa, Tania Tinoco, Roberto Bonafont, entre otros.

Si bien la mayoría de estos comunicadores han sido figuras de televisión, ya sea comentaristas deportivos, reporteros, y presentadores de noticias, no todos trabajan en su marca personal, quizá por el tiempo que conlleva generar su identidad digital o branding personal. Este es el caso de Alfonso Espinoza de los Monteros, quien por su larga trayectoria en televisión es reconocido por el público, su nombre es una marca, sin embargo no ha aprovechado los canales digitales para generar aún más reconocimiento y obtener mayores beneficios.

Del resto de periodistas se destacan: Alberto Astudillo, Andrés Guschmer, Vito Muñoz, y Diego Arcos quienes han sabido conjugar su popularidad en los medios de comunicación tradicionales con lo digital y crear su marca. Para conocer el manejo que estos profesionales le otorgan a su marca, se realizó un monitoreo de sus redes sociales.

Alberto Astudillo, reconocido periodista deportivo, en su página de Instagram tiene alrededor de 22,2 k seguidores, sus post son constantes dentro de esta red social, abarca 3074 publicaciones. En sus fotografías demuestra su pasión por el deporte y los animales.

En su página de Facebook tiene información relevante, tanto de su vida personal como profesional, posee 35007 seguidores en esta red social, al igual que Instagram maneja el tema del deporte y los animales. La interacción es permanente con sus seguidores. En Twitter son 53238 seguidores, 77940 tweets y 102544 me gusta. Se centra en compartir información deportiva y reflejar su gusto por los animales. Sus publicaciones son diarias. En cuanto al tema de marca personal, si bien mantiene sus redes sociales, no maneja una línea gráfica, no cuenta con un dominio que pueda enlazar todo lo que él es y hace.

Otro de los periodistas reconocidos en el ámbito deportivo es Andrés Gushmer. En su página de Twitter tiene 731 mil seguidores, sus post son alrededor de 80,3 mil y con 3211 me gusta. La interacción con sus seguidores es constante. En Instagram tiene 1827 post y $1.2 \mathrm{k}$ seguidores, aquí publica sobre su vida personal y profesional. En su página de Facebook se puede notar las siglas (AG abrazo de gol), esta red social no es manejada por el periodista, sino por una empresa de social media. 
Vito Muñoz Ugarte posee su propia marca CEO \& Founder VitoTVO dentro de su página de Linkedln difunde información acerca de su experiencia profesional, además de sus estudios realizados, lugares donde trabaja actualmente, sus aptitudes y validaciones, sus logros, sus intereses. Cuenta con más de 500 contactos. En Instagram tiene 237, 407 seguidores con un promedio de 3 publicaciones diarias, de manera que su contenido es de su vida personal como de su vida profesional. Cabe destacar que las publicaciones que muestran una mayor cantidad de me gusta son las que tienen temas personales. En Twitter ha publicado 555194 mil tuits, con un total de 884 me gusta a su página, y tiene 429309 seguidores. Su contenido es netamente dedicado a temas deportivos, reflejando su pasión por este tipo de temas y realizando un máximo de 12 publicaciones al día.

Diego Arcos cuenta con su página web (http://diegoarcos.com.ec/) en su logotipo se identifican las iniciales de su nombre (DG) en la parte superior izquierda de su página. Dentro de este sitio web es posible encontrar información con respecto al ámbito deportivo, cine, música, tecnología, entre otros. De igual manera posee una cuenta de Twitter, con 561000 seguidores, 149.000 tuits, de donde existe un promedio de 9 y 5 retuits diarios. Esto muestra que el periodista presenta una actividad bastante continua dentro de esta red social. En sus espacios virtuales ubica el link de su página. En su cuenta de Instagram se observa 60400 seguidores y 1542 publicaciones, dando un promedio de 2 publicaciones al día. El público tiene gran interacción con el periodista dentro de esta red social, por lo que sus seguidores tienen en cuenta dar like y dejar un comentario dentro de sus fotografías. Este periodista ha incursionado en el tema de marca personal, para él «tener una marca le permite definir quién es, qué quiere proyectar y transmitir, porque no dependes de nadie, dependes de tu criterio, de tu línea editorial, de tu concepto, de contenidos, de tus historias» (Arcos, 2018).

Diego Arcos (2018) vio la necesidad de construir su marca personal, al principio, según cuenta, fue muy difícil encargarse de todo lo que conlleva este tema, pero aprendió que no podía hacer el trabajo solo, de esta manera contrató a diseñadores gráficos para que manejen en la imagen corporativa, y él de los contenidos que mostrará a sus seguidores en las distintas plataformas digitales que posee.

\section{Discusión y conclusiones}

Después de consultar a los expertos y comunicadores; monitorear las redes sociales de periodista destacados, es necesario identificar los aspectos que permiten construir una marca personal, además analizar si los periodistas ecuatorianos manejan o no este concepto.

Para Navas (2018), la marca personal debe construirse desde el nombre propio del periodista, y no superponer el nombre del medio que era una de la practicas conocidas; es decir, los medios de comunicación invisibilizan al periodista, en este sentido, los profesionales deben revertir esta relación, y recuperar su marca propia (nombre y apellido) deben recurrir a las plataformas digitales, para que su identidad sea reconocida por su nombre, por su estilo y no solamente por el endoso del medio de comunicación.

La marca del periodista debe construirse desde su aspecto personal profesional y no debe anclarse al medio de comunicación al que representa, por ello es importante que cada contenido o información que publique lo haga responsablemente desde su marca. En este sentido, muchos de los periodistas ecuatorianos se han valido del medio de comunicación para ir construyendo su imagen; sin embargo, no todos han incursionado en mantener esa imagen en plataformas digitales y quienes de alguna manera lo están haciendo no lo manejan dentro del concepto de marca personal. 


\section{La marca personal, un desafío para los Periodistas Ecuatorianos}

Existen muchas herramientas y plataformas digitales que el periodista puede utilizar para dar a conocer su marca personal y ser un canal de comunicación para la comunidad, blog, pagina web, redes sociales, entre otras; pero no necesariamente se debe utilizar todos, sin embargo, una de las herramientas más importantes para darse a conocer y tener una presencia de marca personal es el Twitter que es una red social que se ha convertido en un aliado del periodista por lo que es fundamental su uso diario y periódico.

Los periodistas deben ser responsables del contenido que comparten, ya que esto debe generar confianza y credibilidad en los usuarios que lo siguen, hoy es muy común encontrar noticias e información falsa por lo que es indispensable que la construcción de una marca del periodista tenga bases sólidas de ética, esto genera empatía con la comunidad

Además, para construir marca personal es necesario que el periodista tenga en cuenta en el uso de su marca la utilización de elementos distintivos: una buena fotografía, la representación gráfica mediante el diseño de un logotipo, el uso de la cromática, la búsqueda y aplicación de un buen nombre o naming que sea fácil de recordar y pronunciar; además del contenido que publican en las plataformas digitales. Visto de esta forma la marca personal es la suma de identidad gráfica + contenidos + plataformas digitales, esta fórmula es la que deberían aplicar los periodistas para generar un branding personal.

El periodista no puede generar solo su identidad digital, para esto necesita recurrir a otros especialistas que le proporcionen las herramientas que le permitan posicionarse en el mercado, ser reconocido por su nombre y por el manejo adecuado de los contenidos, así podrá medir el impacto en sus públicos.

Es aconsejable que el periodista gestione sus plataformas, saber qué se dice de él ayudará a mejorar la calidad con la que realiza su trabajo. Por tal razón es necesario separar lo profesional de lo personal.

Una marca es una promesa de valor. Las marcas desprenden valores y generan expectativas, cuesta construirlas y es fácil que se erosionen con el tiempo.

Hay una gran diferencia entre tener o no tener una actividad en línea. "Si no la tenemos es como si no existiéramos» (Cobo, 2012, p. 23), por lo que el periodista se ha visto en la necesidad de tener su propia marca personal dividiendo la vida laboral de la profesional.

De lo anterior, se puede mencionar que de los periodistas analizados en este estudio no hacen una distinción entre lo personal y lo profesional, esto se puede observar en plataformas como Facebook e Instagram donde hay una mezcla de contenidos e imágenes de ambas actividades.

Finalmente en Ecuador, tanto los periodistas de la generación anterior como los nuevos cada vez se van acoplando al uso de las diferentes herramientas digitales; sin embargo, no se evidencia un trabajo planificado y consiente de lo que se debe hacer en los medios digitales, pocos periodistas realmente entienden su funcionamiento. 
La marca personal, un desafío para los Periodistas Ecuatorianos

\section{Referencias}

Arcos, D. (comunicación personal, 05 septiembre 2018)

Arqués, N. (2011). Y tú, ¿qué marca eres? 14 claves para gestionar tu reputación personal. Barcelona. Alienta.

Astudillo, A. (comunicación personal, 05 septiembre 2018)

Baños, M.; Rodríguez, T. (2012). Imagen de marca y product placement, Madrid. ESIC.

Cobo, S., (2012). Periodista, la marca eres tú. Cuadernos de Comunicación evoca. 7. El futuro del periodismo. Madrid. P. 23-28.

Costa, J. (2006). Imagen corporativa en el siglo XXI. Buenos Aires: Crujia.

Estalella, D. (2011). Claves para construir y comunicar una marca personal. Revista luris. 35.

Flórez, C. (2012). Plataforma de Innovación para el sector textil - confección. Medellin: (s.e)

López-Meri, A. y Casero-Ripollés, A. (2017). Las estrategias de los periodistas para la construcción de marca personal en Twitter: posicionamiento, curación de contenidos, personalización y especialización. Revista Mediterránea de Comunicación / Mediterranean Journal of Communication, 8(1), 59-73.

Losada, José. (2010). Marca personal. Revista Comunicación, No. 27 p. 23-32. Medellín.

Méndez, M., Romero, N. y Somavilla, R. (2016). La importancia de la identidad digital del periodista. Nuevos retos para el periodista: innovación, creación y emprendimiento. España. Valencia : Tirant, 2016 p. 44-63.

Muñoz-Olivencia, M. (2015). Propuesta para mejorar la visibilidad en internet de una PYME: uso de web, redes sociales y técnicas de posicionamiento. Jaén. Universidad de Jaén.

Navas, A.(comunicación personal, 16 septiembre 2018)

Rivera, J. ( comunicación personal, 11septiembre 2018)

Sánchez, H. (2017). Pensar y practicar la publicidad desde el Sur. In Libro de Actas del I Congreso Iberoamericano de Investigadores en Publicidad. Ciespal. p. 8191.

Vanegas, K. (s.f.). ¿Cómo crear una marca digital?. [Mensaje en un blog]. Recuperado de https://blog.dinterweb.com/crear-una-marca-digital

Verd, V. (2007). Yo y tú, objetos de lujo, Barcelona, DeBolsillo, 118-119. 
Samuel Yánez - Mayra Martínez -Renato Barros

La marca personal, un desafío para los Periodistas Ecuatorianos

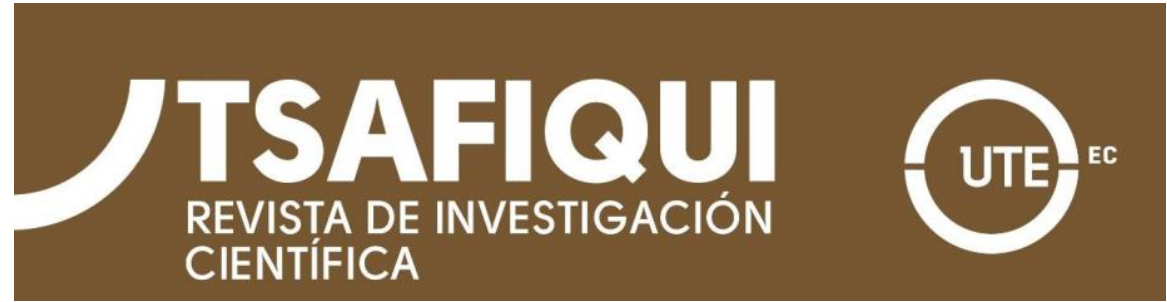

Universidad Tecnológica Equinoccial / CC BY Tsafiqui, Revista de investigación científica, №11, 2018 